The saving of fuel by the adoption of this contrivance is very marked, as is proved by the fact that the temperature of the products of combustion when they leave the box is considerably lower than when they enter it.

The apparatus, which is not unsightly, as it is practically concealed by the ornamental stove in front of it, has been in operation for the past twenty years without causing any trouble or requiring any repairs.

Now fuel is scarce, economisers such as the one described might be adopted with advantage.

48 Princes Gardens, South Kensington, R. C. Parsons. S.W.7, December 16 .

The Perception of Sound.

I would beg permission to add a brief correction to $m y$ remarks relative to the quotation from Helmholtz given by Sir Thomas Wrightson, since I may have been guilty of some misunderstanding. Sir Joseph Larmor has been kind enough to explain to me how the relation between the wave-length of the vibrations set up in a closed volume of liquid by a vibrating body immersed in it and the dimensions of this body is of importance in the case of the cochlea.

The time taken by the compression to travel from the oval window to the round window is so short in comparison with the wave-length that there can be only a very minute difference of pressure between the two sides of the basilar membrane due to this cause. The movement of the fluid as a whole will be the means by which the membrane is set into backward and forward movement. If different parts of the membrane, however, have their own rates of vibration, these parts would be set into resonant vibration by the appropriate rates of alternation of current, on account of the differences of pressure on the two sides of the membrane implied by the flow of liquid. The quotation from Helmholtz seems to suggest that he had come to look upon these movements of the liquid as the actual exciting cause of the local resonance. If so, it may be that the most satisfactory solution of the many difficulties of the case is in a combination of part of Sir Thomas Wrightson's view with the resonance theory of Helmholtz.

W. M. Bayliss.

\section{The Meteoric Shower of December.}

THE weather proved very unfavourable for observation during the first half of December this year, and I watched for a return of these meteors on three nights only, viz. the 6 th, 8 th, and $9^{\text {th. The tem- }}$ perature was unusually high for the period, the mean being $49.5^{\circ}$, and about $9^{\circ}$ in excess of the average. Few Geminids were recorded on December 6 , but on December 8 and 9 , between $I_{3} h$. and $i_{5} h$., they were more numerous, and the place of the radiant admitted of accurate determination. There seems no question that the position moves to the eastward, with the time, similarly to the Lyrid and Perseid radiants. From observations obtained at Bristol in recent years the Geminid centre came out as follows :-

I9I6 December
I9I2
I9I4
I9I8
I9I 8
I9I4
I9I5
I9I7
I914

$$
\begin{aligned}
& \text { R.A. Dec. } \\
& \text { IO2 }+3 \\
& \text {... } 104 \frac{1}{2}+33 \\
& \text {... } 105+3 \mathrm{I} \\
& \text {... } 107+32 \\
& \text {... } 108+33 \\
& \text {.. } 109+33 \\
& \text {... I IO + } 33 \\
& \text {... } 112+33 \\
& \text { i.. II } 4+33
\end{aligned}
$$

Bristol, December I8.

\section{Lady Roberts's Field Glass Fund.}

MAY I, through the hospitality of your columns, ask all officers and others who have received glasses or telescopes on loan through my Fund to send them back to me now for return to their owners? All instruments lent through my Fund bear the letters N.S.L. (National Service League), followed by a letter and a number. I should be glad if officers and others returning glasses would enclose in the case a note of acknowledgment for the owner.

I wish to record my gratitude, not only to the public for the munificent loan of 30,000 glasses, but also to the Press for the valued help which it has given this undertaking

The address for glasses and correspondence is the Manager, Lady Roberts's Field Glass Fund, 64 Victoria Street, S.W.I. ROBERTS.

\section{INTER-ALLIED CONFERENCE ON INTER-} NATIONAL ORGANISATIONS IN SCIENCE.

THIS important conference was held in Paris on November 26-29. Primarily, it was a conference of the Committee of Inquiry (Commission d'Etudes) which was constituted at a meeting of representatives of academies of the Allied countries and the United States of America held in London, on the invitation of the Royal Society, early in October last.

The Committee of Inquiry was to "prepare a general scheme of international organisations to meet the requirements of the various branches of scientific and industrial research, including those relating to national defence." At the London conference certain resolutions had been passed and proposals submitted, and the duty of the Paris conference was to weld these into a workable whole and generally to establish on a sound basis an international council or federation of national councils which would be representative in each country of academies and other scientific societies.

The names of the delegates, who met in Paris to the number of forty-seven, are given in the following list:-Belgium-MM. Lecointe, Massart, de la Vallée Poussin; Brazil-M. de Carvalho; France-MM. Painlevé, Guignard, E. Picard, A. Lacroix, Lippmann, E. Perrier, Roux, Haller, Bigourdan, Baillaud, Lallemand, Moureu, Flahault; Italy - Sen. V. Volterra, Profs. Reina, Nasini, Ricco, Fantoli; Japan-Profs. Tanakadate and Sakurai; Poland-M. L. Mickiewicz; Rumania-MM. Soutzo, Hurmuzeco, Mrazee, Marinesco; Serbia-MM. Zujovic, Petrovitch, Jopovitch; United Kingdom-Prof. Schuster, Mr. J. H. Jeans, Sir Frank Dyson, Sir E. Sharpey Schafer, Profs. Frankland, Sherrington, and Starling, Col. Lyons, Dr. Knott; United States of America-Prof. Bumstead, Col. Carty, Drs. Durand, Flexner, Hale, Noyes. Although the Academy of Athens had not been able to send representatives, Greece must also be included in the list of countries invited to form national research councils.

On the morning of Tuesday, November 26 , the representatives met in the Academy of Sciences, and were welcomed in a short address by $\mathrm{M}$. Painlevé. It was then proposed that Prof.

NO. 2565 , VOL. IO2] 